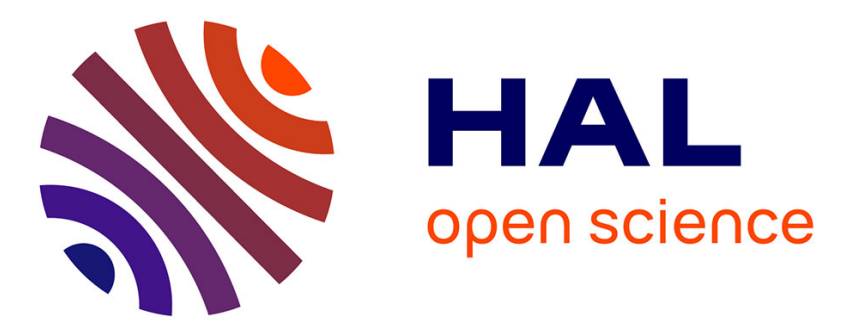

\title{
The micro-pulling-down growth of Tm:LuAG and Tm,Pr:LuAG crystals and optical properties
}

Qiu Li, Zhangli Shi, Qingsong Song, Jie Tian, Jian Liu, Xiaodong Xu, Jun $\mathrm{Xu}$, Dongzhen Li, Kheirreddine Lebbou

\section{- To cite this version:}

Qiu Li, Zhangli Shi, Qingsong Song, Jie Tian, Jian Liu, et al.. The micro-pulling-down growth of Tm:LuAG and Tm,Pr:LuAG crystals and optical properties. Optical Materials, 2021, 118, pp.111275. 10.1016/j.optmat.2021.111275 . hal-03299166

\section{HAL Id: hal-03299166 https://hal.science/hal-03299166}

Submitted on 8 Nov 2021

HAL is a multi-disciplinary open access archive for the deposit and dissemination of scientific research documents, whether they are published or not. The documents may come from teaching and research institutions in France or abroad, or from public or private research centers.
L'archive ouverte pluridisciplinaire HAL, est destinée au dépôt et à la diffusion de documents scientifiques de niveau recherche, publiés ou non, émanant des établissements d'enseignement et de recherche français ou étrangers, des laboratoires publics ou privés. 


\title{
The micro-pulling-down growth of Tm:LuAG and Tm,Pr:LuAG crystals and optical properties
}

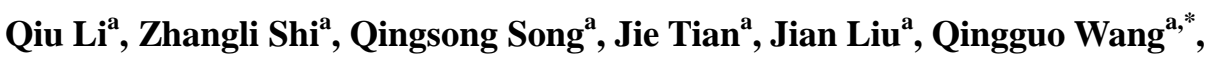
Xiaodong $\mathrm{Xu}^{\mathrm{b}, *}$, Jun $\mathrm{Xu}^{\mathrm{a}}$, Kheirreddine Lebbou ${ }^{\mathrm{c}, *}$

\begin{abstract}
a School of Physics Science and Engineering, Institute for Advanced Study, Tongji University, Shanghai 200092, China

b Jiangsu Key Laboratory of Advanced Laser Materials and Devices, School of Physics and Electronic Engineering, Jiangsu Normal University, Xuzhou 221116, China

c Institut Lumière Matière, UMR5306 Université Lyon1-CNRS, Université de Lyon, Lyon 69622, Villeurbanne Cedex, France
\end{abstract}

${ }^{*}$ Corresponding authors.

E-mail addresses: xdxu79@jsnu.edu.cn (X. Xu), wqingguo2013@163.com (Q. Wang)

kheirreddine.lebbou@univ-lyon1.fr (K. Lebbou)

\begin{abstract}
:
$\mathrm{Tm}^{3+}$ doped and $\mathrm{Tm}^{3+}, \mathrm{Pr}^{3+}$ co-doped $\mathrm{Lu}_{3} \mathrm{Al}_{5} \mathrm{O}_{12}$ (LuAG) single crystals have been successfully grown by the micro-pulling-down ( $\mu$-PD) method. The absorption spectra, fluorescence spectra and lifetimes were investigated at room temperature. In the absorption spectra, the transition centered at $782 \mathrm{~nm}$ matches well with the GaAlAs LDs laser pumping. The incorporation of $\mathrm{Pr}^{3+}$ into $\mathrm{Tm}^{3+}$-doped LuAG crystals significantly enhanced the intensity of $1.5 \mu \mathrm{m}$ emission and decreased the fluorescence lifetime of the lower energy level for 1.5 $\mu \mathrm{m}$ emission from $10.427 \mathrm{~ms}$ to $2.603 \mathrm{~ms}$. The results indicate that Tm,Pr:LuAG crystal can be promising candidate for near infrared $1.5 \mu \mathrm{m}$ laser materials.
\end{abstract}

Keywords: Tm, $\operatorname{Pr}: \mathrm{Lu}_{3} \mathrm{Al}_{5} \mathrm{O}_{12}$; Micro-pulling-down ( $\mu$-PD) method; Near-infrared laser 


\section{Introduction}

Laser sources operating at $1.5 \mu \mathrm{m}$ region have attracted much attention due to the use for remote sensing, biomedical systems, optical subscriber networks, telecommunication industry, and so on [1-3]. Using an AlGaAs diode laser as pump source, trivalent thulium $\left(\mathrm{Tm}^{3+}\right)$ can provide laser oscillation at this specific wavelength through the ${ }^{3} \mathrm{H}_{4} \rightarrow{ }^{3} \mathrm{~F}_{4}$ transition channel. However, the transition of $\mathrm{Tm}^{3+}$ that generates emission around $1.5 \mu \mathrm{m}$ is considered to be self-terminating, for the lifetime of ${ }^{3} \mathrm{~F}_{4}$ energy level is much longer than that of ${ }^{3} \mathrm{H}_{4}$ energy level [4]. In order to deal with the unfavorable population bottleneck and depopulate the ${ }^{3} \mathrm{~F}_{4}$ state efficiently, co-doping sensitive ions like $\mathrm{Tb}^{3+}, \mathrm{Ho}^{3+}$ and $\mathrm{Pr}^{3+}$ ions were proposed to quench the terminal ${ }^{3} \mathrm{~F}_{4}$ level and increase the emission intensity at around $1.5 \mu \mathrm{m}$ by means of energy transfer [5-9].

$\mathrm{Lu}_{3} \mathrm{Al}_{5} \mathrm{O}_{12}$ (LuAG) is a promising laser host material due to its relatively high thermal conductivity, chemical and physical stability [10]. Tm:LuAG crystal can be easily grown by the Czochralski method [11] and micro-pulling-down method [12]. In 1995, A diode-pumped Tm:LuAG laser was demonstrated with a relatively low optical-to-optical efficiency of 7.3\% [13]. For continuous-wave operation, a maximum output power of $4.91 \mathrm{~W}$ was reported with a slope efficiency of $25.3 \%$ [14]. To the best of our knowledge, there has no research about the growth and performance of Tm,Pr:LuAG crystal.

In this work, Tm,Pr:LuAG crystal was grown by the micro-pulling-down method. The spectroscopic properties of Tm,Pr:LuAG crystal were reported and $\mathrm{Pr}^{3+}$ ion was demonstrated to be an efficient deactivated ion for $\mathrm{Tm}^{3+}$ ion by effective energy transfer from $\mathrm{Tm}^{3+} .{ }^{3} \mathrm{~F}_{4}$ level to $\operatorname{Pr}^{3+}:^{3} \mathrm{~F}_{2}$ level.

\section{Experiments}

\subsection{Crystal growth}

The 2.0 at. $\% \mathrm{Tm}^{3+}, 0.2$ at.\% $\mathrm{Pr}^{3+}$ co-doped $\mathrm{LuAG}$ and 2.0 at.\% $\mathrm{Tm}^{3+}$ single doped LuAG single crystals were grown by the $\mu$-PD method $[15,16]$. The $\operatorname{Tm}_{2} \mathrm{O}_{3}, \mathrm{Lu}_{2} \mathrm{O}_{3}, \mathrm{Al}_{2} \mathrm{O}_{3}$ and $\operatorname{Pr}_{6} \mathrm{O}_{11}$ powders with purity of $99.999 \%$ were prepared as raw materials. After being mixed, the mixtures were shaped into a rod and pressed by cold isostatic, then sintered at $1300^{\circ} \mathrm{C}$ for 12 $\mathrm{h}$ in a muffle furnace. A <111> oriented LuAG crystal was used as seed and the pulling rate was $0.3 \mathrm{~mm} / \mathrm{min}$. The growth atmosphere was high-purity flowing argon. Fig.1 shows the obtained Tm:LuAG and Tm,Pr:LuAG crystals with diameter of about $2 \mathrm{~mm}$. The crystals are transparent and colorless with homogeneous diameter and free of macroscopic defects.

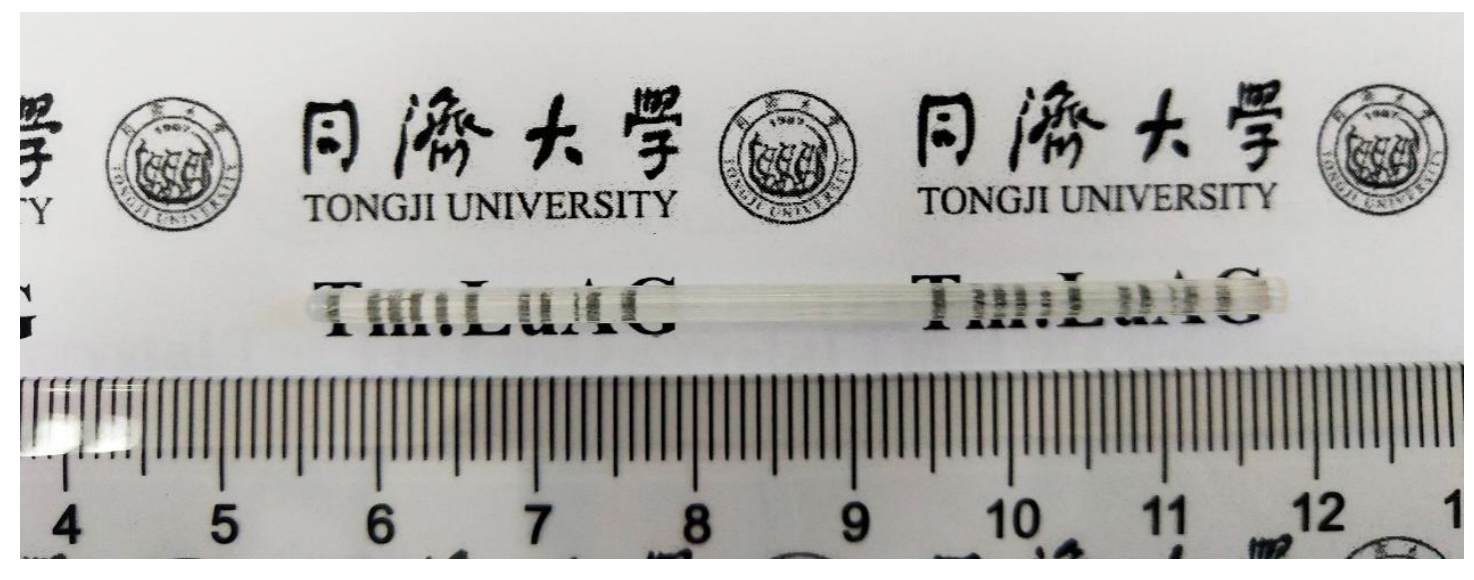




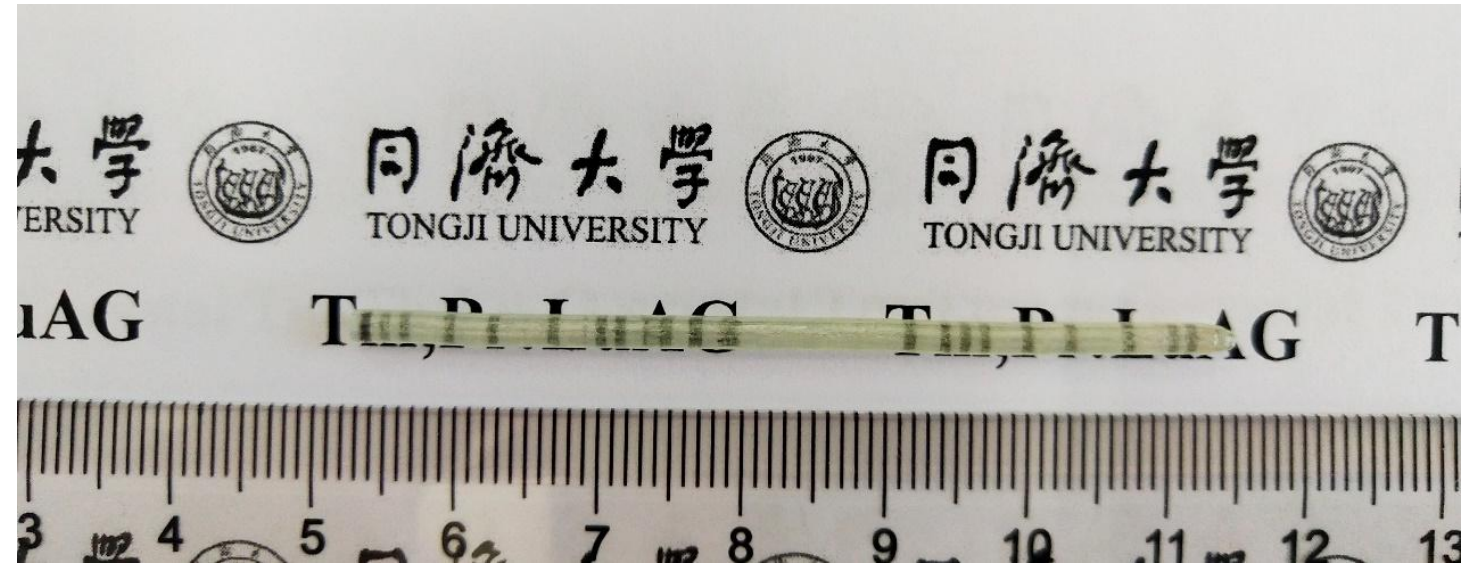

(b)

Fig. 1. Photographs of the as-grown 2.0 at.\% Tm:LuAG (a) and 2.0 at.\% Tm, 0.2 at.\% Pr:LuAG (b) single crystals.

\subsection{Spectral measurements}

The Tm:LuAG and Tm,Pr:LuAG crystal samples were cut from the as-grown crystals and two surfaces were polished for measurements. The absorption spectra of the samples were performed by a spectrometer (Lambda 900, Perkin-Elmer UV-VIS-NIR) in the wavelength range of 400-2100 $\mathrm{nm}$. An Edinburgh Instruments FLS 980 spectrophotometer was used to measure the emission spectra and decay curves under the excitation of $790 \mathrm{~nm}$. All the measurements of the samples above were taken at room temperature.

\section{Results and discussion}

\subsection{Absorption spectra}

The room temperature absorption spectra of Tm:LuAG and Tm,Pr:LuAG single crystals in the wavelength range of 400-2000 $\mathrm{nm}$ are shown in Fig. 2. The five absorption bands of Tm:LuAG crystal centered at 460, 681, 782, 1178 and $1632 \mathrm{~nm}$ correspond to the transitions from the ground state ${ }^{3} \mathrm{H}_{6}$ to the excited states ${ }^{1} \mathrm{D}_{2},{ }^{1} \mathrm{G}_{4},{ }^{3} \mathrm{~F}_{2,3},{ }^{3} \mathrm{H}_{4},{ }^{3} \mathrm{H}_{5}$ and ${ }^{3} \mathrm{~F}_{4}$, respectively. The absorption band centered at around $1472 \mathrm{~nm}$, corresponding to the ${ }^{3} \mathrm{H}_{4} \rightarrow{ }^{3} \mathrm{~F}_{4}+{ }^{3} \mathrm{~F}_{3}$ transition of $\mathrm{Pr}^{3+}$ ions, is also clearly in the absorption spectrum of Tm,Pr:LuAG crystal. As is known to all, the transition at $782 \mathrm{~nm}$ matches well with AlGaAs LDs pumping sources. The absorption coefficient at $782 \mathrm{~nm}$ of Tm:LuAG and Tm,Pr:LuAG was calculated to be 1.23 $\mathrm{cm}^{-1}$ and $1.30 \mathrm{~cm}^{-1}$, respectively. Besides, the full width at half maximum (FWHM) of absorption band at $782 \mathrm{~nm}$ was $11.4 \mathrm{~nm}$ and $15.0 \mathrm{~nm}$, respectively. The FWHM is larger than the value of Tm:LYSO (8nm at 791nm [17]), Tm:YAP (3.9 nm at $777 \mathrm{~nm} \mathrm{[18])} \mathrm{and}$ Tm: $\mathrm{KY}_{3} \mathrm{~F}_{10}$ (3.8nm at $\left.778 \mathrm{~nm}[19]\right)$. The absorption bands of Tm:LuAG and Tm,Pr:LuAG crystals around $782 \mathrm{~nm}$ are wide enough to steadily absorb the incident pump power. 


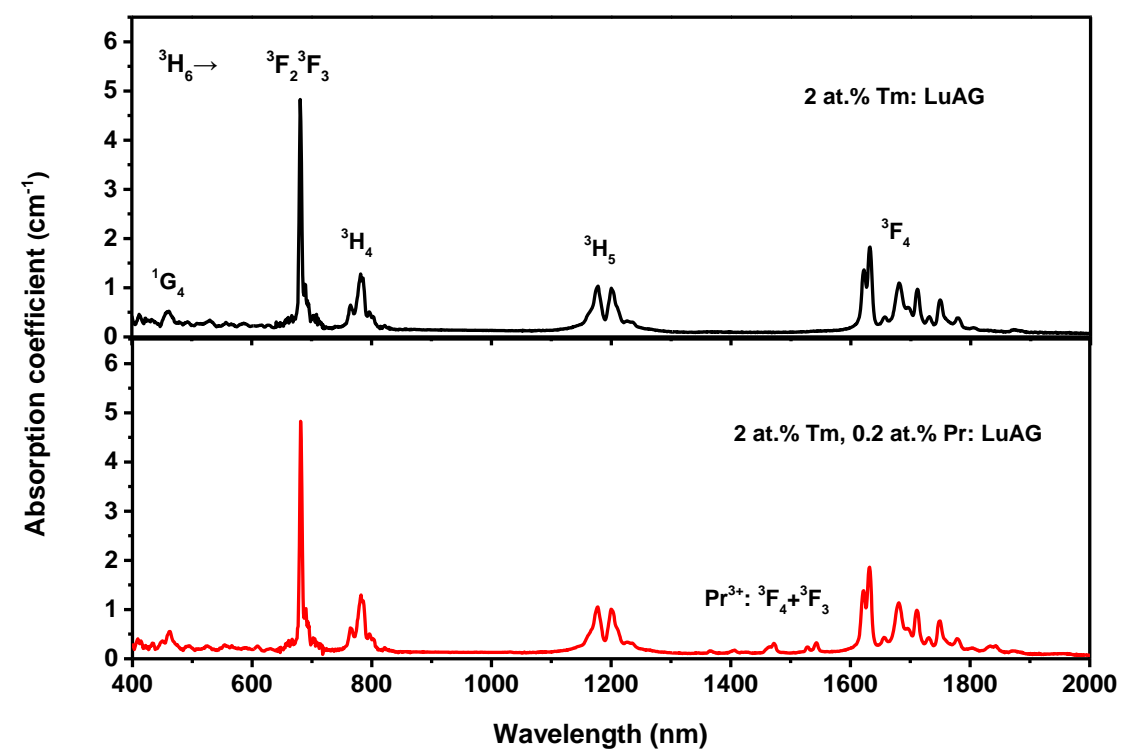

Fig. 2. Room temperature absorption spectra of Tm:LuAG and Tm,Pr:LuAG crystals.

\subsection{Fluorescence spectra}

Fig. 3 shows the fluorescence spectra of Tm:LuAG and Tm,Pr:LuAG crystals under 790 $\mathrm{nm}$ excitation at room temperature. Both samples have similar emission bands around 1431 $\mathrm{nm}$, which correspond to the ${ }^{3} \mathrm{H}_{4} \rightarrow{ }^{3} \mathrm{~F}_{4}$ transition of $\mathrm{Tm}^{3+}$ ions. As can be seen from Fig. 3, the intensity of the emission line around $1431 \mathrm{~nm}$ increased after the introduction of $\mathrm{Pr}^{3+}$ ions. The enhanced fluorescence emission of the ${ }^{3} \mathrm{H}_{4} \rightarrow{ }^{3} \mathrm{~F}_{4}$ transition can justify that the introduction of $\mathrm{Pr}^{3+}$ ions can depopulate the $\mathrm{Tm}^{3+}:{ }^{3} \mathrm{~F}_{4}$ level effectively. The results suggest that Tm,Pr:LuAG crystal could be a promising material for $1.5 \mu \mathrm{m}$ laser generation.

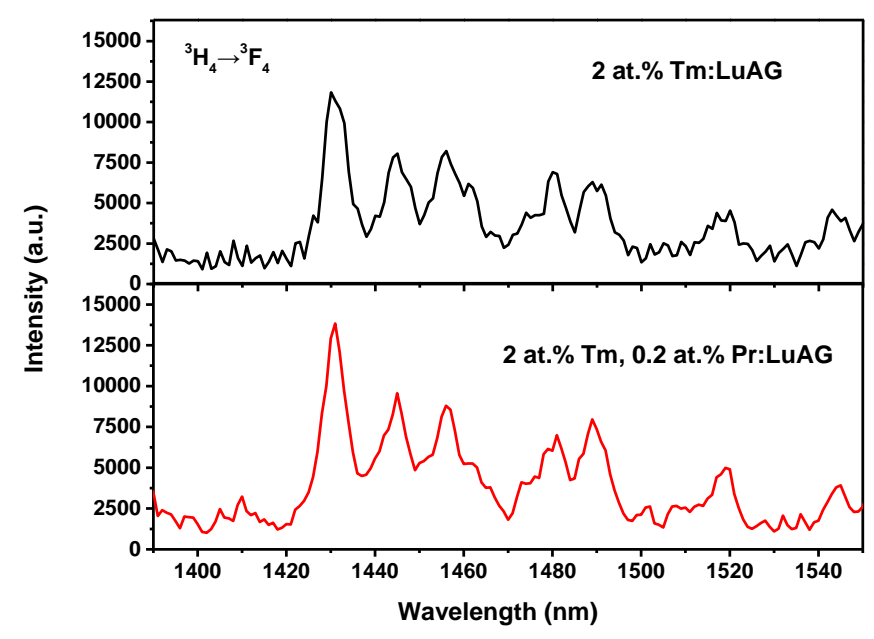


Fig. 3. Room temperature fluorescence spectra of Tm:LuAG and Tm,Pr:LuAG crystals.

\section{3 fluorescence lifetime}

The room-temperature decay curves of ${ }^{3} \mathrm{H}_{4}$ and ${ }^{3} \mathrm{~F}_{4}$ levels of Tm:LuAG and Tm, Pr:LuAG crystals excited by $790 \mathrm{~nm}$ laser are shown in Fig. 4. For Tm:LuAG crystal, the fluorescence lifetimes of ${ }^{3} \mathrm{H}_{4}$ and ${ }^{3} \mathrm{~F}_{4}$ level were measured to be $378 \mu$ s and $10.427 \mathrm{~ms}$, respectively. It can be easily found that the fluorescence lifetime of the ${ }^{3} \mathrm{~F}_{4}$ terminal level is much longer than that of the ${ }^{3} \mathrm{H}_{4}$ initial level. Therefore the laser around $1.5 \mu \mathrm{m}$ is normally self-terminating. In order to depopulate the lower level through the energy transfer process, we introduce $\mathrm{Pr}^{3+}$ ions into Tm:LuAG crystal. Fig. 5 shows the energy level scheme of $\mathrm{Tm}^{3+}$ and $\mathrm{Pr}^{3+}$ ions in LuAG crystal. Under a $790 \mathrm{~nm} \mathrm{LD}$ excitation, the $\mathrm{Tm}^{3+}$ ions are excited from ground state ${ }^{3} \mathrm{H}_{6}$ to the excited state ${ }^{3} \mathrm{H}_{4}$. The fluorescence emission at $1.5 \mu \mathrm{m}$ is due to the $\mathrm{Tm}^{3+}:{ }^{3} \mathrm{H}_{4} \rightarrow{ }^{3} \mathrm{~F}_{4}$ transition. For the $1.8 \mu \mathrm{m}$ emission, the population of ${ }^{3} \mathrm{~F}_{4}$ level is based on the cross relaxation (CR) $\mathrm{Tm}^{3+}:{ }^{3} \mathrm{H}_{4}+{ }^{3} \mathrm{H}_{6} \rightarrow{ }^{3} \mathrm{~F}_{4}+{ }^{3} \mathrm{~F}_{4}$, and the cross relaxation process increased lifetime of ${ }^{3} \mathrm{~F}_{4}$ level [20]. Since the $\operatorname{Pr}^{3+}:{ }^{3} \mathrm{~F}_{2}$ level is adjacent to the $\mathrm{Tm}^{3+}:{ }^{3} \mathrm{~F}_{4}$ level, an effective energy transfer (ET) $\mathrm{Tm}^{3+}:{ }^{3} \mathrm{~F}_{4}+\operatorname{Pr}^{3+}:{ }^{3} \mathrm{H}_{4} \rightarrow \operatorname{Tm}^{3+}:{ }^{3} \mathrm{H}_{6}+\operatorname{Pr}^{3+}:{ }^{3} \mathrm{~F}_{2}$ will depopulate the $\mathrm{Tm}^{3+}:{ }^{3} \mathrm{~F}_{4}$ level. To verify the mechanism, the lifetimes of ${ }^{3} \mathrm{H}_{4}$ and ${ }^{3} \mathrm{~F}_{4}$ levels of Tm,Pr:LuAG crystal are compared with those of Tm:LuAG crystal. By co-doping $\mathrm{Pr}^{3+}$ ions into Tm:LuAG crystals, the lifetime of ${ }^{3} \mathrm{~F}_{4}$ level decreased greatly to $2.603 \mathrm{~ms}$, while the lifetime of ${ }^{3} \mathrm{H}_{4}$ level experienced a slight decrease from $378 \mu$ s to $346 \mu$ s. The lifetime of ${ }^{3} \mathrm{H}_{4}$ level of Tm,Pr:LuAG crystal is much higher than the value of $0.5 \% \mathrm{Tm}, 1 \% \mathrm{~Tb}: \mathrm{YVO}_{4}\left(50 \mu \mathrm{s}\right.$ [7), 0.5\% Tm: $\mathrm{GdScO}_{3}$

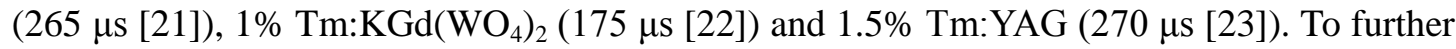
investigate the effect of $\mathrm{Pr}^{3+}$ ions, the energy transfer efficiency $\eta$ was calculated according to the flowing formula:

$$
\eta_{E T}=1-\tau_{T m / P r} / \tau_{T m}
$$

where $\tau_{T m}$ and $\tau_{T m / P r}$ are the fluorescence lifetimes of Tm:LuAG and Tm,Pr:LuAG crystals, respectively. The measured fluorescence lifetimes $\tau$ and calculated energy transfer efficiency $\eta$ of Tm:LuAG and Tm,Pr:LuAG crystals are listed in Table 1. The he energy transfer efficiency from $\mathrm{Tm}^{3+}:{ }^{3} \mathrm{~F}_{4}$ level to $\operatorname{Pr}^{3+}:{ }^{3} \mathrm{~F}_{2}$ level was calculated to be75.0\%. The results indicate that the co-doping of $\operatorname{Pr}^{3+}$ ions can effectively depopulate ${ }^{3} \mathrm{~F}_{4}$ lower level, while has little influence on the ${ }^{3} \mathrm{H}_{4}$ upper level. Therefore, the co-doping of $\mathrm{Pr}^{3+}$ ions into $\mathrm{Tm}^{3+}$ doped crystals can be used as an effective way for $1.5 \mu \mathrm{m}$ laser operation.
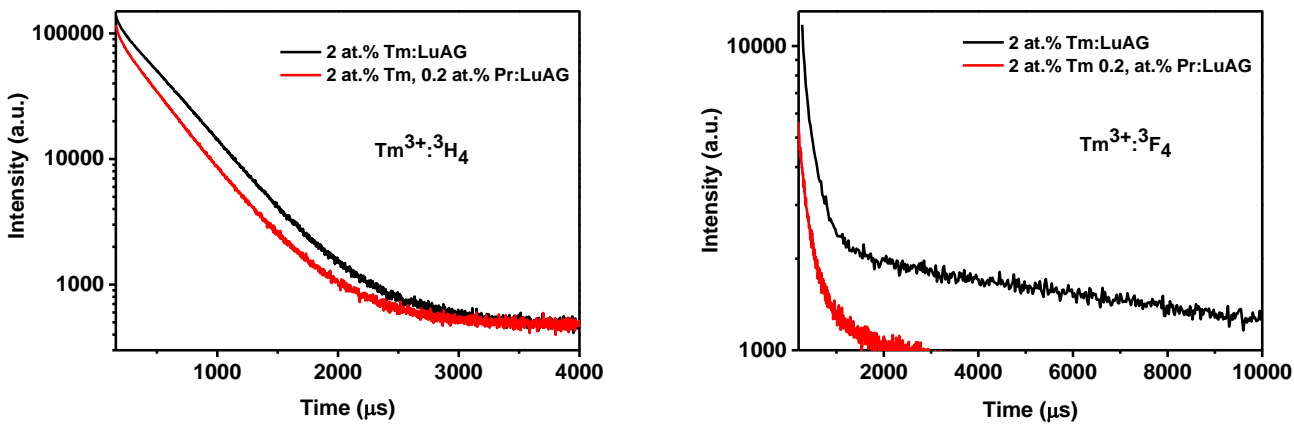

Fig.4. Fluorescence decay curves of the ${ }^{3} \mathrm{H}_{4}$ and ${ }^{3} \mathrm{~F}_{4}$ mainfold of Tm:LuAG and Tm,Pr:LuAG crystals. 


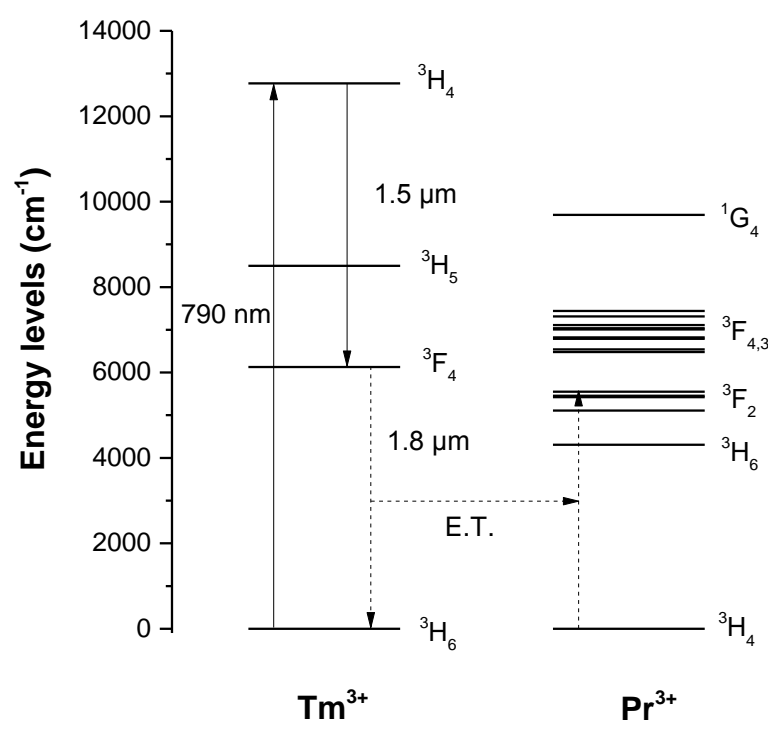

Fig.5. Energy level diagram of $\operatorname{Tm}^{3+}, \operatorname{Pr}^{3+}$ co-doped system.

Table 1 Fluorescence lifetimes $\tau$ and fluorescence quantum efficiencies $\eta$ for the Tm:LuAG and Tm, Pr:LuAG crystals.

\begin{tabular}{llll}
\hline Tm:LuAG & $\tau(\mu \mathrm{s}){ }^{3} \mathrm{H}_{4}$ & $\tau(\mathrm{ms}){ }^{3} \mathrm{~F}_{4}$ & $\eta{ }^{3} \mathrm{~F}_{4}$ \\
\hline $2 \% \mathrm{Tm}$ & 378 & 10.427 & \\
$2 \% \mathrm{Tm}, 0.2 \% \mathrm{Pr}$ & 346 & 2.603 & $75.0 \%$ \\
\hline
\end{tabular}

\section{Conclusion}

In conclusion, $\mathrm{Tm}^{3+}$ and $\mathrm{Tm}^{3+}, \mathrm{Pr}^{3+}$ co-doped LuAG single crystals were successfully grown by the $\mu$-PD method. Compared with Tm:LuAG crystal, the absorption coefficient and FWHM at $782 \mathrm{~nm}$ of $\mathrm{Tm}^{3+}, \mathrm{Pr}^{3+}$ co-doped LuAG crystal is higher. It was also demonstrated that after the introduction of $\operatorname{Pr}^{3+}$ ions, the intensity of $1.5 \mu \mathrm{m}$ emission increased and the fluorescence lifetime of $\mathrm{Tm}^{3+}:{ }^{3} \mathrm{~F}_{4}$ level decreased greatly from $10.427 \mathrm{~ms}$ to $2.603 \mathrm{~ms}$, while the lifetime of $\mathrm{Tm}^{3+}{ }^{3} \mathrm{H}_{4}$ level changed little from $378 \mu$ s to $346 \mu$ s. $\mathrm{Pr}^{3+}$ ions can efficiently depopulate the ${ }^{3} \mathrm{~F}_{4}$ lower level, while having little influence on the ${ }^{3} \mathrm{H}_{4}$ upper level of $\mathrm{Tm}^{3+}$ ions. All the results show that Tm,Pr:LuAG crystal could be a potential laser material for eye-safe $1.5 \mu \mathrm{m}$ laser operation.

\section{Acknowledgements}

This work is partially supported by National Natural Science Foundation of China (No. 61621001) and "Qinglan Project" of the Young and Middle-aged Academic Leader of Jiangsu College and University. 


\section{References}

[1] P. Zhang, Z. Chem, Y. Hang, Z. Li, H. Yin, S. Zhu, S. Fu, A. Li, Enhanced emission of the 1.5-1.67 $\mu \mathrm{m}$ fluorescence in $\mathrm{Er}^{3+}, \mathrm{Ce}^{3+}$-codoped $\mathrm{Lu}_{3} \mathrm{Al}_{5} \mathrm{O}_{12}$ crystal, J. Alloys Compd. 696 (2017) 795-798

[2] D. M. Shi, Y. G. Zhao, Q. Qian, D. D. Chen, Q. Y. Yang, Role of PbO substitution by $\mathrm{Bi}_{2} \mathrm{O}_{3}$ on $1.47 \mu$ m luminescence properties of $\mathrm{Tm}^{3+} / \mathrm{Tb}^{3+}$-doped $\mathrm{Bi}_{2} \mathrm{O}_{3}-\mathrm{GeO}_{2}-\mathrm{Ga}_{2} \mathrm{O}_{3}$ glass, J. Alloys Compd. 499 (2010) 126-130

[3] P. A. Burns, J. M. Dawes, P. Dekker, J. A. Piper, H. Jiang, J. Wang, Optimization of Er, Yb:YCOB for CW laser operation, IEEE J. Quantum Electron. 40 (2004) 1575-1582.

[4] R. M. Percival, D. Szebesta, J. R. Williams, Highly efficient $1.064 \mu \mathrm{m}$ upconversion pumped $1.47 \mu \mathrm{m}$ thulium doped fluoride fibre laser, Electron. Lett. 30 (1994) 1057-1058 [5] P. Zhang, X. Huang, R. Wang, Z. Li, H. Yin, S. Zhu, Z. Chen, Y. Hang, Enhanced $1.4 \mu \mathrm{m}$ emissions of $\mathrm{Tm}^{3+}$ via $\mathrm{Tb}^{3+}$ deactivation in $\left(\mathrm{Gd}_{0.5} \mathrm{Lu}_{0.5}\right)_{2} \mathrm{SiO}_{5}$ crystal, Opt. Mater. Express 8 (2018) 668-675.

[6] G. H. Rosenblatt, R. C. Stoneman, L. Esterowitz, Diode-Pumped Room-Temperature cw $1.45 \mu \mathrm{m}$ Tm,Tb:YLF laser, Advanced Solid State Lasers, Optical Society of America, Salt Lake City, Utah, 1990: p. DPL8.

[7] F. S. Ermeneux, C. Goutaudier, R. Moncorge, M. T. Cohen-Adad, M. Bettinelli, E. Cavalli, Growth and fluorescence properties of $\mathrm{Tm}^{3+}$ doped $\mathrm{YVO}_{4}$ and $\mathrm{Y}_{2} \mathrm{O}_{3}$ single crystals, Opt. Mater. 8 (1993) 83-90

[8] R. C. Stoneman, L. Esterowitz, Continuous-wave 1.50- $\mu$ m thulium cascade laser, Opt. Lett. 16 (1991) 232-234.

[9] Z. Mazurak, M. Czaja, R. Lisiecki, J. Gabrys'-Pisarska, Optical properties of the $\mathrm{Tm}^{3+}$ and energy transfer between $\mathrm{Tm}^{3+} \rightarrow \mathrm{Pr}^{3+}$ ions in $\mathrm{P}_{2} \mathrm{O}_{5}-\mathrm{CaO}-\mathrm{SrO}-\mathrm{BaO}$ phosphate glass, Opt. Mater. 33 (2011) 506-510.

[10] M. Sugiyama, Y. Fujimoto, T. Yanagida, D. Totsuka, Y. Yokota, A. Yoshikawa, Scintillation properties of Tm-doped $\mathrm{Lu}_{3} \mathrm{Al}_{5} \mathrm{O}_{12}$ single crystals, Opt. Mater. 34 (2011) 439443.

[11] X. Xu, X. Wang, Z. Lin, Y. Cheng, D. Li, S. Cheng, F. Wu, Z. Zhao, C. Gao, M. Gao, J. $\mathrm{Xu}$, Crystal growth, spectroscopic and laser properties of Tm:LuAG crystal, Laser Phys. Lett. 19 (2009) 2140-2143

[12] Q. Song, X. Xu, Z. Zhou, B. Xu, Laser Operation In a Tm:LuAG Crystal Grown By the Micro-pulling-down Technique, IEEE Photon. Technol. Lett. 30 (2018) 1913-1916.

[13] N. P. Barnes, M. G. Jani, R. L. Hutcheson, Diode-pumped, room-temperature Tm:LuAG laser, Appl. Opt. 34 (1995) 4290-4294.

[14] C. T. Wu, Y. L. Ju, Y. F. Li, Z. G. Wang, Diode-pumped Tm:LuAG laser at room temperature, Chin. Opt. Lett. 6 (2008) 415-416.

[15] Y. Xue, N. Li, D. Wang, Q. Wang, B. Liu, Q. Song, D. Li, X. Xu, H. Gu, Z. Qin, G. Xie, Z. Wang, J. Xu, Spectroscopic and laser properties of Tm:CNGG crytsals grown by he micropulling-down method, J. Lumin. 213 (2019) 36-39

[16] J. Xu, Q. Song, J. Liu, S. Zhou, Y. Pan, D. Li, P. Liu, X. Xu, Y. Ding, J. Xu, K. Lebbou, Spectroscopic characteristics of $\mathrm{Dy}^{3+}$-doped $\mathrm{Y}_{3} \mathrm{Al}_{5} \mathrm{O}_{12}$ (YAG) and $\mathrm{Y}_{3} \mathrm{ScAl}_{4} \mathrm{O}_{12}$ (YSAG) garent single crystals grown by the micro-pulling-down method, J. Lumin. 215 (2019) 116675

[17] J. Di, X. Xu, C. Xia, D. Zhou, Growth, crystal structure and optical study of 
Tm:LuYSiO 5 single crystal, Mater. Res. Bull. 50 (2014) 374-378.

[18] L. Guillemot, P. Loiko, A. Braud, Continuous-wave Tm: $\mathrm{YAlO}_{3}$ laser at $\sim 2.3 \mu \mathrm{m}$, Opt. Lett. 44 (2019) 5077-5080.

[19] L. Guillemot, P. Loiko, R. Souland, A. Braud, Close look on cubic Tm:KY ${ }_{3} \mathrm{~F}_{10}$ crystal for highly efficient lasing on the ${ }^{3} \mathrm{H}_{4} \rightarrow{ }^{3} \mathrm{H}_{5}$ transition, Opt. Express 28 (2020) 3451-3463.

[20] T. Sasikala, L. Rama Moorthy, Photoluminescence properties of singly doped $\mathrm{Tm}^{3+}$ and co-doped $\mathrm{Tm}^{3+} / \mathrm{Tb}^{3+}$ ions in tellurite glasses, J. Mol. Struct. 1076 (2014) 529-534.

[21] Q. Li, J. Dong, Q. Wang, Y. Xue, H. Tang, X. Xu, J. Xu, Crystal growth, spectroscopic characteristics, and Judd-Ofelt analysis of Tm: $\mathrm{GdScO}_{3}$, Opt. Mater. 109 (2020) 110298

[22] F. Güell, X. Mateos, J. Gavaldà, R. Solé, M. Aguiló, Blue luminescence in $\mathrm{Tm}^{3+}$-doped $\mathrm{KGd}\left(\mathrm{WO}_{4}\right)_{2}$ single crystals, J. Lumin. 106 (2004) 109-114.

[23] V. Sudesh, J.A. Piper, Spectroscopy, modeling, and laser operation of thulium-doped crystals at $2.3 \mu \mathrm{m}$, IEEE J. Quantum Electron. 36 (2000) 879-884. 